\title{
The evolving management of laryngeal neuroendocrine carcinomas
}

\author{
Alfio Ferlito · James S. Lewis Jr • Alessandra Rinaldo
}

Received: 21 May 2011/ Accepted: 6 June 2011/Published online: 17 June 2011

(C) Springer-Verlag 2011

Laryngeal neuroendocrine neoplasms are divided into two broad categories based on their tissue of origin: epithelial and neural [1]. Laryngeal epithelial neuroendocrine neoplasms are all malignant lesions (carcinomas) and are a subset of neoplasms that share specific morphologic, histochemical, immunohistochemical, ultrastructural and molecular characteristics. The major categories of laryngeal neuroendocrine carcinomas are typical carcinoid (well differentiated neuroendocrine carcinoma), atypical carcinoid (moderately differentiated neuroendocrine carcinoma), small cell neuroendocrine carcinoma (poorly differentiated neuroendocrine carcinoma) and large cell neuroendocrine carcinoma (poorly differentiated neuroendocrine carcinoma) [2]. The neural category consists only of paraganglioma which is invariably benign [3]. Although neuroendocrine neoplasms are uncommon in the larynx, they represent the most common non-squamous neoplasms arising in this area and to date more than 700 cases of them have been reported in the literature [1].

The atypical carcinoid is the most frequent laryngeal neuroendocrine carcinoma, followed by small cell neuroendocrine carcinoma, carcinoid tumor, and large cell neuroendocrine carcinoma. However, in the past large cell neuroendocrine carcinoma was classified under the

This paper was written by members of the International Head and Neck Scientific Group (www.IHNSG.com).

A. Ferlito $(\bowtie) \cdot$ A. Rinaldo

ENT Clinic, University of Udine, Piazzale S. Maria della

Misericordia, 33100 Udine, Italy

e-mail: a.ferlito@uniud.it

J. S. Lewis Jr

Department of Pathology and Immunology, Washington

University School of Medicine, St. Louis, MO, USA umbrella term of atypical carcinoid so it may actually be more common than previously realized [4].

Accurate classification of the laryngeal epithelial neuroendocrine carcinomas requires knowledge of specific pathologic criteria separating the major categories. Neuroendocrine carcinomas of the larynx have widely varying prognosis, clinical management, and response to therapy. Thus, accurate classification is essential. Immunohistochemistry is an important diagnostic adjunct in the evaluation of these tumors, as it allows for definitive demonstration of neuroendocrine differentiation.

For typical carcinoid, conservation surgery, particularly supraglottic laryngectomy, may be suitable because the supraglottis is the most frequent site of involvement. Transoral $\mathrm{CO}_{2}$ laser surgery can be a good alternative for appropriate cases because of the functional results and lower morbidity [5]. Elective neck dissection is not warranted. Bilateral selective neck dissection (levels II and III) is only indicated for clinically or pathologically proven cervical metastases [6].

The mainstay of treatment for atypical carcinoid of the larynx is surgical resection. As most tumors are located in the supraglottis, supraglottic laryngectomy is often the procedure of choice. Transoral $\mathrm{CO}_{2}$ laser surgery has been also employed to resect these tumors with oncologically sound results and with low morbidity [7]. Elective neck dissection appears to be warranted in view of the high incidence of both early cervical metastasis and subsequent involvement of cervical lymph nodes. Bilateral dissection of sublevel IIA and level III is only adequate for elective surgical treatment of the neck in supraglottic tumors [8]. Bilateral selective neck dissection (levels II and III) should be used therapeutically for metastatic disease. Post-operative radiotherapy is indicated in the presence of cervical lymph node metastases. Painful skin metastases from an 
atypical carcinoid of the larynx have been treated successfully with $\mathrm{CO}_{2}$ laser resection [9].

For laryngeal small cell neuroendocrine carcinoma a therapeutic protocol using a combination of local irradiation and chemotherapy, similar to that in pulmonary small cell carcinoma, is indicated [10]. The commonly used chemotherapeutic agents are cyclophosphamide, doxorubicin, vincristine, methotrexate and lomustine. Radical surgical procedures (total laryngectomy and radical neck dissection) have failed in the majority of cases reported. The survival rate is similar to that of small cell lung cancer [11].

Laryngeal large cell neuroendocrine carcinoma is a newly described clinicopathological entity, and therapy is not standardized for this tumor. Similar to the situation in cases from the lung, considerable debate has emerged as to whether this tumor should be treated as small cell neuroendocrine carcinoma or in different ways. In consideration of the aggressive behavior of this neoplasm, there is a great need to develop novel and effective systemic treatment [12].

With their wide range of clinical behaviors, it is very important for clinicians and pathologists to be familiar with the existence of different types of neuroendocrine carcinomas of the larynx.

\section{References}

1. Ferlito A, Silver CE, Bradford CR, Rinaldo A (2009) Neuroendocrine neoplasms of the larynx: an overview. Head Neck 31:1634-1646
2. Lewis JS Jr, Ferlito A, Gnepp DR, Rinaldo A, Devaney KO, Silver CE, Travis WD (2011) Terminology and classification of neuroendocrine neoplasms of the larynx. Laryngoscope 121:1187-1193

3. Devaney KO, Ferlito A, Rinaldo A (2010) Neuroendocrine carcinomas of the larynx: what do the different histologic types really mean? Eur Arch Otorhinolaryngol 267:1323-1325 [Editorial]

4. Lewis JS Jr, Spence DC, Chiosea S, Barnes EL Jr, BrandweinGensler M, El-Mofty SK (2010) Large cell neuroendocrine carcinoma of the larynx: definition of an entity. Head Neck Pathol 4:198-207

5. Cevizci R, Karakullukçu B, van den Brekel MW, Balm AJ (2010) Laser excision of a typical carcinoid tumor of the larynx: a case report. Kulak Burun Bogaz Ihtis Derg 20:305-308

6. Ferlito A, Devaney KO, Rinaldo A (2006) Neuroendocrine neoplasms of the larynx: advances in identification, understanding and management. Oral Oncol 42:770-788

7. Chang KP, Lee LY, Yeh AR, Dai TS, Hao SP (2005) Endoscopic $\mathrm{CO}_{2}$ laser surgery for an atypical carcinoid tumor of the epiglottis masquerading as a supraglottic cyst. Head Neck 27:1004-1007

8. Ferlito A, Silver CE, Rinaldo A (2008) Selective neck dissection (IIA, III): a rational replacement for complete functional neck dissection in patients with N0 supraglottic and glottic squamous carcinoma. Laryngoscope 118:676-679

9. Simpson LK, Ostlere LS, Harland C, Gharaie S (2009) Treatment with carbon dioxide laser of painful skin metastases from a laryngeal neuroendocrine carcinoma. Clin Exp Dermatol 34:e873e875

10. Ferlito A, Shaha AR, Rinaldo A (2002) Neuroendocrine neoplasms of the larynx: diagnosis, treatment and prognosis. ORL J Otorhinolaryngol Relat Spec 64:108-113

11. Ferlito A, Rinaldo A (2008) Primary and secondary small cell neuroendocrine carcinoma of the larynx: a review. Head Neck 30:518-524

12. Patel KJ, Chandana SR, Wiese DA, Olsen B, Conley BA (2010) Unusual presentation of large-cell poorly differentiated neuroendocrine carcinoma of the epiglottis. J Clin Oncol 28:e461-e463 